Journal of Advanced Research in Fluid Mechanics and Thermal Sciences

\title{
Optimization of Impact Energy of Copper-Polylactic Acid (Cu-PLA) Composite Using Response Surface Methodology for FDM 3D Printing
}

\author{
Arvind Kottasamy ${ }^{1,2}$, Mahendran Samykano ${ }^{3,}{ }^{,}$, Kumaran Kadirgama ${ }^{2}$, Devarajan Ramasamy ${ }^{3}$, Md \\ Mustafizur Rahman ${ }^{3}$, Adarsh Kumar Pandey ${ }^{4}$

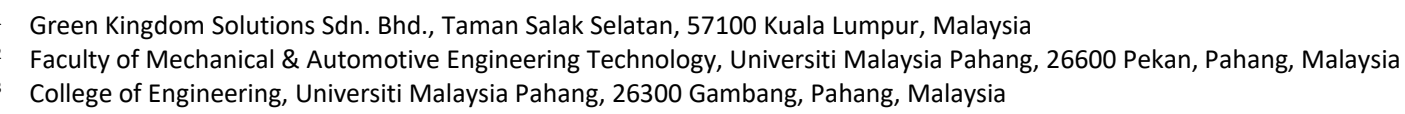

\section{Article history:}

Received 31 December 2020

Received in revised form 23 May 2021

Accepted 29 May 2021

Available online 27 June 2021

\section{Keywords:}

Impact Energy; Response Surface Methodology; Cu-PLA; ANOVA; Energy Absorption

\begin{abstract}
This study attempts to provide a statistical evaluation of the effect of $\mathrm{Cu}$ wt.\% and infill pattern on the FDM-based 3D printed parts' impact properties. The developed model is based on the acquired experimental data accompanied by response surface methodology (RSM) analysis. The confidence level for RSM is set to $95 \%(\alpha=0.05)$, where $P$-value lower than 0.05 shows a significant effect by the parameter. Besides determining significant parameters, this analysis also provides modeling of impact properties and optimizes the desired mechanical performance parameter. ANOVA analysis includes data of standard deviation (S), coefficient of determination $\left(R^{2}\right)$, adjusted and predicted $\left(R^{2}\right)$. Infill pattern and Cu wt.\% show a significant effect on both factors, including energy absorbed and impact strength. The model created for the energy absorbed, and impact strength has an error of $7.23 \%$ and $6.60 \%$. The maximum energy absorbed and impact strength obtained through optimization is $2.5180 \mathrm{~J}$ and $35.3657 \mathrm{~kJ} / \mathrm{m}^{2}$, respectively, through the combination of two main factors, including a Concentric infill pattern with $25 \mathrm{wt} . \% \mathrm{Cu}$. The highest energy absorbed is achieved by the Concentric infill pattern with $2.7 \mathrm{~J}$ by $25 \mathrm{wt} . \% \mathrm{Cu}$ and $1.39 \mathrm{~J}$ by $80 \mathrm{wt} . \% \mathrm{Cu}$. The Grid infill pattern has the lowest energy absorbed, recording $0.63 \mathrm{~J}$ and $0.41 \mathrm{~J}$ for 25 and 80 wt.\% copper composition. The mathematical models of the impact properties were also developed using RSM, focusing on varying copper composition and infill patterns, which can be used to predict desired impact properties.
\end{abstract}

\section{Introduction}

The emergence of additive manufacturing (AM) has attracted manufacturers' great interest due to its technological advantages. The procedure of merging several layers of materials to fabricate a three-dimensional (3D) model that was first designed in digital software is called AM [1, 2]. Digital models' production through computer software simplifies the production of complex geometry

\footnotetext{
* Corresponding author.

E-mail address: mahendran@ump.edu.my
}

https://doi.org/10.37934/arfmts.84.1.7890 
compared to traditional fabrication methods of removing raw material. The AM method comprised of various techniques such as fused deposition modeling (FDM) [3], stereo-lithography (SLA) [4], powder bed fusion (PBF) [5], material jetting [6], laminated object manufacturing (LOM) [7], and direct energy deposition (DED) [8]. FDM technique works on the basis of the material-extrusion process in additive manufacturing [9]. Filaments play a vital role in the efficiency of the FDM technique, which is deposited layer-by-layer on the adopted substrate. The developed products through the FDM technique are considered to have anisotropic mechanical properties. It is realized that mechanical anisotropy is the biggest for the FDM technique at approximately $50 \%$ compared to other additive manufacturing processes [10]. The filament's mechanical strength is usually better than the product's mechanical strength since the product strength depends significantly on the adhesion strength between each layer of melted materials. The mechanical performance of final products through 3D printing techniques is entirely dependent on effective parameters such as printing pattern, melting temperature, the thickness of printed layers, and fill density. Sood et al., [11] investigated the dimensional accuracy of the final product through the FDM technique. They observed that shrinkage is dominant along the length and width direction of the built part. Another study conducted by Sun et al., [12] evaluated the effect of processing conditions on the bonding quality of the FDM technique and observed creep deformation to dominate changes in the mesostructure. Zhang et al., [13] concluded that the interaction between the road width and the layer thickness are effective factors on the part distortions in the FDM technique. Nancharaiah et al., [14] reported that the layer thickness and road width are effective parameters on part accuracy of FDM components. Abbott et al., [15] concluded that print speed has a large impact on tensile strength, with high speeds generally yielding lower strength.

These parameters can cause critical drawbacks such as distortion in between layers, which might reduce FDM parts' mechanical strength [16].

Polymer filaments have been extensively used in the 3D printing industry as efficient filaments due to their lightweight, cost-effective, and flexible processing abilities. However, the disadvantages of these polymers are low mechanical properties and shortening their use for the production of functional parts. In recent years, various materials have been integrated into polymers to form polymer-matrix composites (PMC) to achieve the desired mechanical properties and functionality of polymers in the AM process. Promising results have been achieved in new composite materials reinforced with small particles, fibers, or nanomaterials [17-20]. Polylactic acid (PLA) filament is one of the most commonly used polymer materials besides ABS [21, 22]. PLA has exhibited very promising performance as a highly versatile material for the additive manufacturing process with the advantage of being biomaterial and decomposable [23]. Similar to ABS, PLA has a low thermal expansion coefficient, which reduces the risk of the solidified layer not adhering to the previous surface, causing warping and large components that crack while printing [24]. PLA possesses some unique specifications, such as a relatively low melting point $\left(15-160^{\circ} \mathrm{C}\right)$, which reduces the energy demand for printing processes and provides an advantage for off-grid applications $[25,26]$. The tensile strength of PLA can vary from 15.5 to $72 \mathrm{MPa}$ [27]. PLA printed with open-source FDM printer conducted in standard conditions for normal users found to be around 56.6 MPa [28]. Research also found that 3D printed PLA has better mechanical properties in comparison with the injected molded PLA [29].

Particle reinforcements are most commonly used to form PMC due to their low cost. Iron and copper powders have been added to ABS, which resulted in improved modulus, thermal conductivity, and reduced thermal expansion [30, 31]. Moreover, the inclusion of iron and copper particles into polymers has exhibited promising performance to overcome the thermal expansion challenges, which is one of the major issues related to polymers' use in the FDM technique. In the preservation 
of parent material, mechanical properties were discovered in PLA reinforced with iron that showed a negligible reduction in strength and improved conductivity properties. The addition of metallic particles into the polymer matrix generally showed a decrease in mechanical properties. However, it is still possible for certain metal fillers and polymer matrix combinations with suitable composition to retain the parent material's mechanical properties. Ko et al., [32] investigated the mechanical properties of PLA-containing Poly (Glycolic acid) fibers and reposted better performance in terms of tensile and flexural strength for the developed composites due to the presence of induced fibers. $\mathrm{Hu}$ et al., [33] developed PLA based composite incorporated with carbon fiber and revealed better results in terms of tensile modulus, strength, and energy absorption. In a research work conducted by Siakeng et al., [34], authors investigated the effect of pineapple leaf fibers as reinforcement within PLA on the mechanical properties of the developed composites. They concluded that the use of leaf fibers has an impressive impact on the strength resulted from the developed composites.

The present study investigates the impacts of copper concentration and infill pattern on the printed parts' impact properties through the 3D printing technique. A statistical model is developed based on the acquired experimental results accompanied by response surface methodology analysis. This is the first study to investigate the effects of copper composition and infill patterns on the FDM 3D printing technique's impact properties using response surface methodology to the best of the authors' knowledge. A developed polymer-matrix composite (CU-PLA) with a variation of copper inclusion and infill patterns is considered for this analysis. The highest energy absorbed is achieved by the Concentric infill pattern with $2.7 \mathrm{~J}$ by $25 \mathrm{wt} . \% \mathrm{Cu}$ and $1.39 \mathrm{~J}$ by $80 \mathrm{wt} . \% \mathrm{Cu}$. The Grid infill pattern has the lowest energy absorbed, recording $0.63 \mathrm{~J}$ and $0.41 \mathrm{~J}$ for 25 and $80 \mathrm{wt} \%$ copper composition. The confidence level is set to $95 \%(\alpha=0.05)$, where $P$-value lower than 0.05 shows a significant effect by the parameter. Besides determining significant parameters, this analysis also provides modeling of impact properties and optimizes the desired mechanical performance parameter. The mathematical models of the impact properties were also developed using response surface methodology, focusing on varying copper composition and infill patterns, which can be used to predict desired mechanical properties. According to the findings of this research study, the maximum energy absorbed and impact strength can be obtained through the combination of effective parameters, including a Concentric infill pattern with 25 wt.\% copper composition.

\section{Materials and Methods}

The material selected for this study is copper reinforced PLA polymer. Copper is well known for its high corrosion resistance, good thermal and electrical conductivity [35]. Copper's reflectivity has caused porosities using the laser-based process [36, 37]. Hence, FDM could be a good alternative for printing copper powders in the polymer matrix as its reflectivity does not affect the printing process. The selected copper particles reinforced by PLA filaments are Copper Fill from ColorFabb and Copper Metal Filled from Gizmo Dorks. The details of the filaments can be seen in Table 1. The selected 3D printer is WANHAO Duplicator i3 Desktop 3D Printer. The adopted 3D printer can achieve a temperature up to $240{ }^{\circ} \mathrm{C}$ and uses an MK10 nozzle that is widely available in the market. The specimens have been printed with different infill patterns (Rectilinear, Grid, Concentric, Octagramspiral, and Honeycomb) in order to study their mechanical properties. The infill patterns were set constant at $50 \%$ infill density for all test specimens. The geometry of test specimens was fabricated according to ASTM standard using a low-cost FDM printer. 
Table 1

Specifications of Copper reinforced PLA filament from Manufacturer

\begin{tabular}{lll}
\hline & Copper Fill & Copper Metal Filled \\
\hline Manufacturer & ColorFabb & Gizmo Dorks \\
Copper particle composition wt.\% & Approx. 80\% & Approx. 25\% \\
Diameter & $1.75 \mathrm{~mm}$ & $1.75 \mathrm{~mm}$ \\
Extrusion Temperature & $190-225^{\circ} \mathrm{C}$ & $195-220^{\circ} \mathrm{C}$ \\
Bed Temperature & $50-60^{\circ} \mathrm{C}$ & $60^{\circ} \mathrm{C}$ \\
\hline
\end{tabular}

\subsection{Printing Process of The Specimen}

The test specimen is designed using SOLIDWORKS 2017 edition software. The test specimen's dimension is based on the ASTM standards with respect to the specific mechanical performance test. The generated CAD model through SOLIDWORKS software is converted into an STL file. In this research work, the Repetier-Host is adopted as the slicing software due to its simple interface/accuracy in the generation of required g-code. The major factors such as the visual g-code interface and a DTL composer play a vital role in allowing the STL file's visualization on a plate.

\subsection{Machine Constant Parameter}

Several parameters of the machine need to be defined and set constant to avoid extensive variation during the printing process as it may affect the consistency of the printing process. Aside from the infill pattern and raster angle, all other parameters were kept constant. The machine parameters that have been kept constant in this study are shown in Table 2.

\section{Table 2}

Constant parameters during the printing process

\begin{tabular}{ll}
\hline Parameters & Constants \\
\hline Layer height & $0.3 \mathrm{~mm}$ \\
Initial layer height & $0.3 \mathrm{~mm}$ \\
Horizontal Shell: solid layer & Top: 1 layer, Bottom: 1 layer \\
Outer Perimeter & 2 \\
Nozzle diameter & $0.4 \mathrm{~mm}$ \\
Filament diameter & $1.75 \mathrm{~mm}( \pm 0.05 \mathrm{~mm})$ \\
Extruder temperature & $210^{\circ} \mathrm{C}\left( \pm 2^{\circ} \mathrm{C}\right)$ \\
Printing speed & $30 \mathrm{~mm} / \mathrm{s}$ \\
Print bed temperature & $60^{\circ} \mathrm{C}\left( \pm 2^{\circ} \mathrm{C}\right)$ \\
\hline
\end{tabular}

\subsection{Impact Test}

Impact test indicates the resistance property of a material to failure due to a suddenly applied force. Therefore, impact energy or energy absorbed due to fracture can be measured by conducting an impact test. Two types of impact tests are existent for testing the impact properties of a material. The tests are known as the Charpy impact test and Izod impact test. The difference between both tests is in the way the test material is placed. For the Izod impact test, the specimen will be placed in a vertical position, whereas, for the Charpy impact test, the specimen is placed horizontally. Besides that, in the Izod impact test, the specimen's notch will be facing the hammer. Whereas, in the Charpy impact test, the specimen's notch will be positioned away from the hammer. Since the Izod impact test is the standard testing procedure for comparing the impact resistance of plastic, it was chosen 
for this research. The standard that has been adopted to conduct the impact test on that 3D printed specimen is ASTM D256. The standard geometry for the impact test specimen is shown in Figure 1.

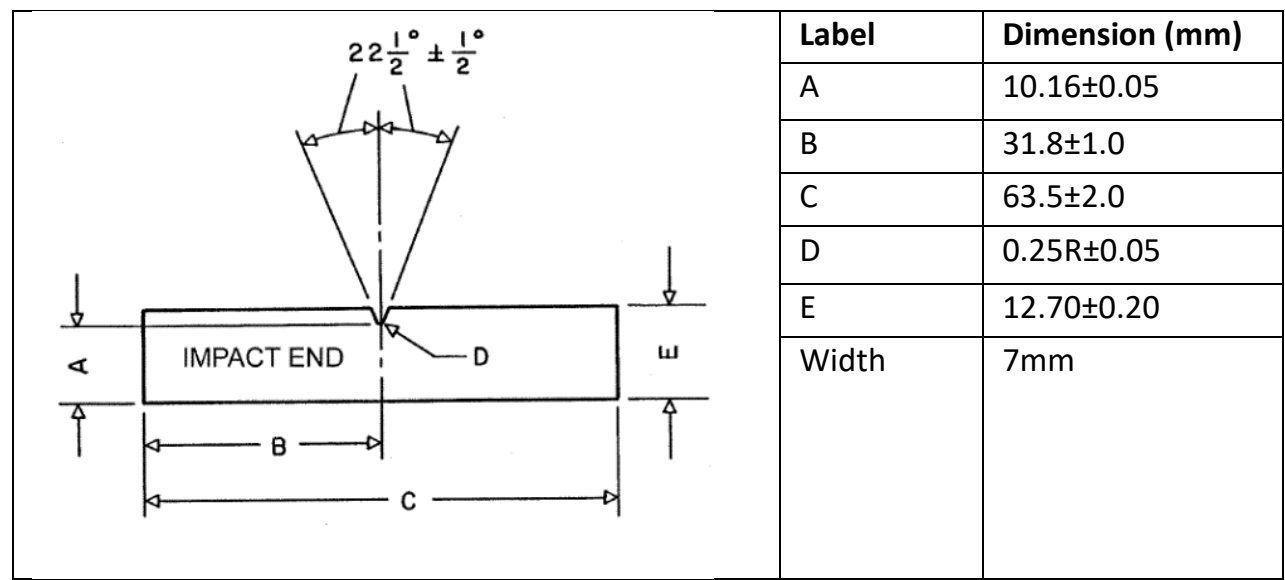

Fig. 1. Specimen Geometry according to ASTM D256. Source: (ASTM D256,2014)

\section{Results and Discussion}

Impact test results indicate the toughness and sensitivity of a structure towards the notched area. The amount of energy absorbed by the fabricated specimen is the key point for determining toughness and notch sensitivity. The absorbed energy is the amount of energy that the specimen absorbed during the entire impact test. As of ASTM D256-10 standard reporting, the impact strength is also included. Impact strength is derived from a division of energy absorbed with the area under notch and represented in $\mathrm{kJ} / \mathrm{m}^{2}$. Table 3 , tabulates the average energy absorbed $(\mathrm{J})$ and impact strength $\left(\mathrm{kJ} / \mathrm{m}^{2}\right)$ for both $\mathrm{Cu}$ composition specimens with respective infill patterns.

Table 3

Experimental results of average energy absorbed and impact strength

\begin{tabular}{lllll}
\hline \multirow{2}{*}{ Infill Pattern } & \multicolumn{2}{l}{ Energy Absorbed $(\mathrm{J})$} & \multicolumn{2}{l}{ Impact Strength $\left(\mathrm{kJ} / \mathrm{m}^{2}\right)$} \\
\cline { 2 - 5 } & $25 \mathrm{wt} . \%$ & $80 \mathrm{wt} . \%$ & $25 \mathrm{wt} . \%$ & $80 \mathrm{wt} . \%$ \\
\hline Grid & 0.6320 & 0.4113 & 8.8864 & 5.7837 \\
Octagram-spiral & 0.9750 & 0.4733 & 13.7092 & 6.6554 \\
Rectilinear & 1.3037 & 0.5847 & 18.3305 & 8.2208 \\
Honeycomb & 1.3753 & 0.6615 & 19.3382 & 9.2942 \\
Concentric & 2.6960 & 1.3850 & 37.9078 & 19.4507 \\
\hline
\end{tabular}

According to Table 3 and Figure 2, the highest energy absorbed is acquired by the Concentric infill pattern with $2.7 \mathrm{~J}$ by $25 \mathrm{wt} . \% \mathrm{Cu}$ and $1.39 \mathrm{~J}$ by $80 \mathrm{wt} . \% \mathrm{Cu}$. The Grid infill pattern has the lowest energy absorbed, recording $0.63 \mathrm{~J}$ and $0.41 \mathrm{~J}$ for 25 and $80 \mathrm{wt}$.\% copper composition. Rectilinear infill pattern exhibited the energy absorption value of $1.3 \mathrm{~J}$ by $25 \mathrm{wt} . \% \mathrm{Cu}$. The acquired results are in accordance with the achieved data by Kain et al., [38], since they have proved that there is a direct interaction between the infill pattern and the resulting mechanical performance of the test specimen. From Fig. 2, it was realized that the amount of energy absorption increases in accordance with the following pattern sequence; Grid, Octagram-spiral, Rectilinear, Honeycomb, and Concentric for both 25 and 80 wt.\% copper composition. The energy absorbed by 25 wt.\% copper composition is generally higher than $80 \mathrm{wt} . \% \mathrm{Cu}$, regardless of infill pattern. The significant difference in energy absorption between 25 wt.\% and 80 wt.\% $\mathrm{Cu}$ was observed. The increase in $\mathrm{Cu}$ particles 
concentration in the polymer is anticipated to reduce the molecular bond's strength in the polymer matrix resulting in lower properties.

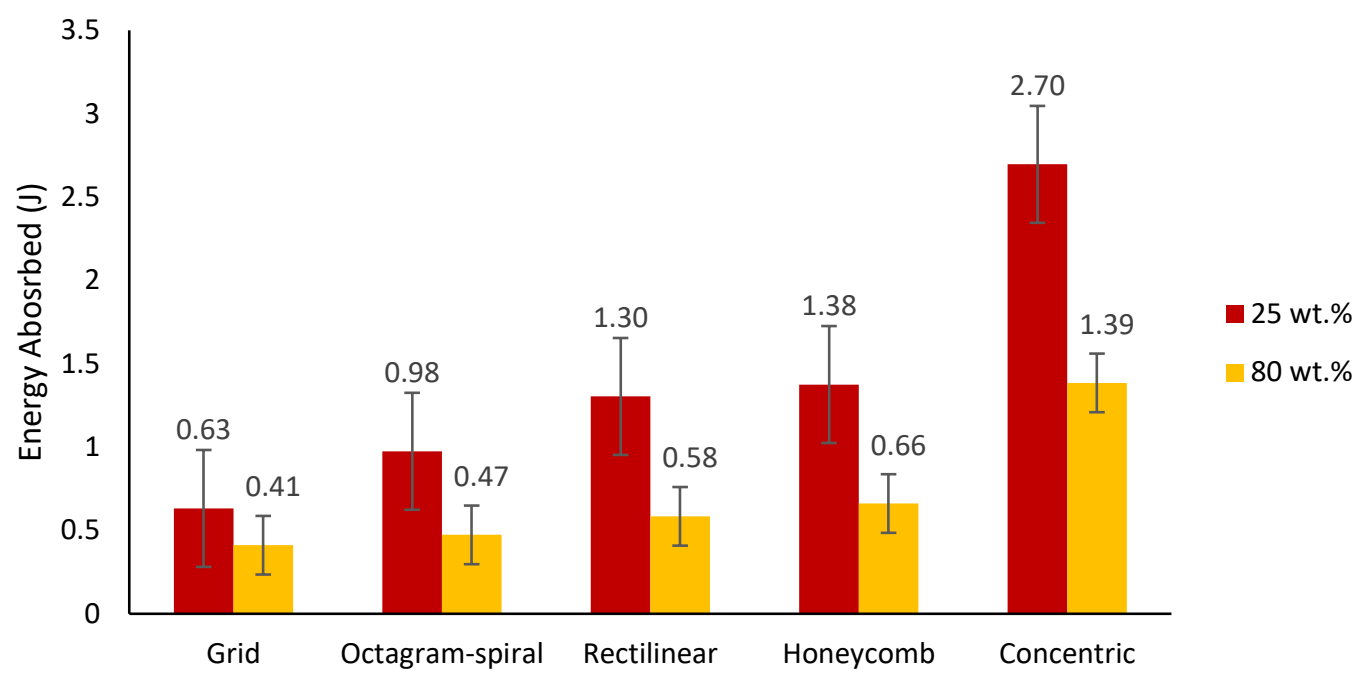

Fig. 2. Experimental results of energy absorbed with respect to various infill patterns

Referring to Table 3 and Figure 3, the highest impact strength is acquired by the Concentric infill pattern with $37.91 \mathrm{~kJ} / \mathrm{m}^{2}$ by $25 \mathrm{wt} . \% \mathrm{Cu}$ and $19.45 \mathrm{~kJ} / \mathrm{m}^{2}$ by $80 \mathrm{wt} . \% \mathrm{Cu}$. The Grid infill pattern has the lowest impact strength recording $8.89 \mathrm{~kJ} / \mathrm{m}^{2}$ and $5.78 \mathrm{~kJ} / \mathrm{m}^{2}$ for 25 and $80 \mathrm{wt} . \%$ copper composition. Rectilinear infill pattern exhibited the impact strength of $18.33 \mathrm{~kJ} / \mathrm{m}^{2}$ by $25 \mathrm{wt} . \% \mathrm{Cu}$. From Figure 3, it was observed that the amount of impact strength enhances in accordance with the following pattern sequence; Grid, Octagram-spiral, Rectilinear, Honeycomb, and Concentric for both 25 and $80 \mathrm{wt}$.\% copper compositions. The impact strength of $25 \mathrm{wt}$.\% copper composition is generally higher than $80 \mathrm{wt} . \% \mathrm{Cu}$, regardless of infill pattern. The significant difference in impact strength between 25 wt.\% and 80 wt.\% Cu was observed. Enhancement in the inclusion of copper particles are believed to reduce the strength of the molecular bond in the polymer matrix [39].

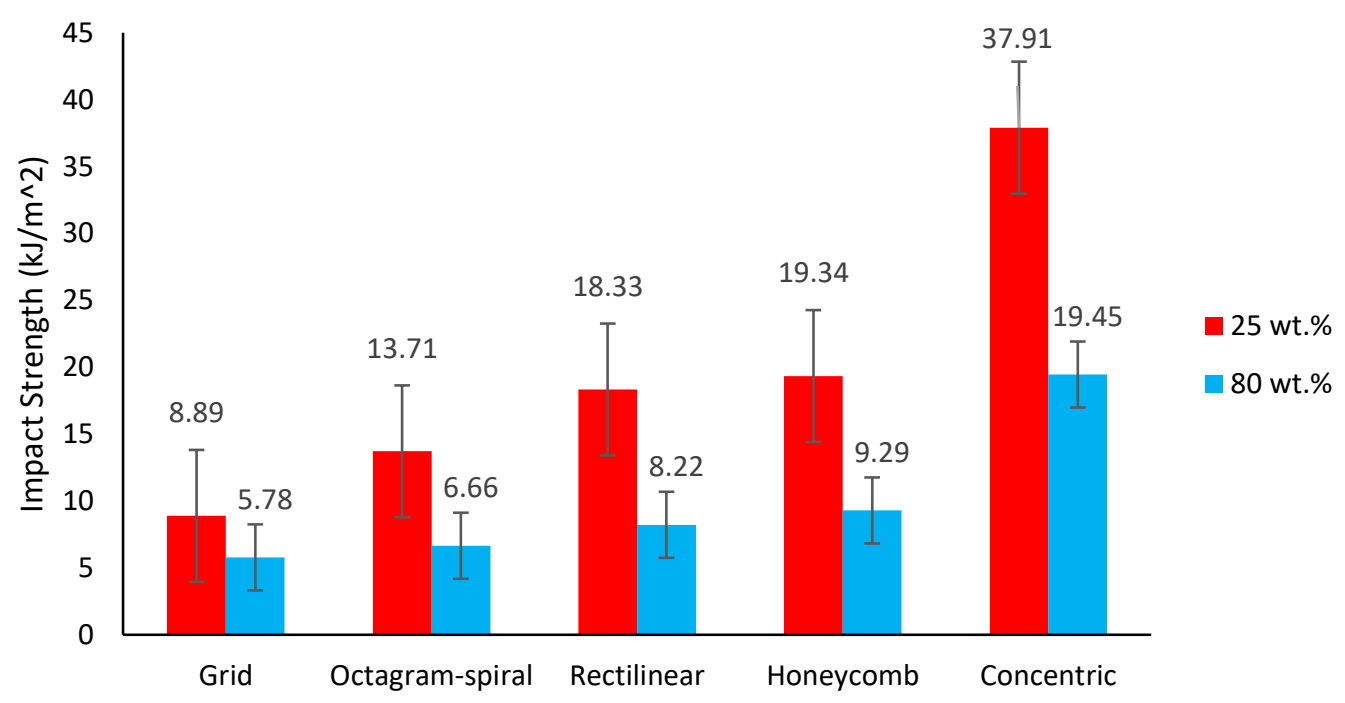

Fig. 3. Experimental results of impact energy with respect to various infill patterns 
Figure 4 shows the Pareto effects of energy absorbed with respective experiment parameters. The illustration shows that the infill pattern has the most significant impact on energy absorbed, followed by $\mathrm{Cu}$ composition. The significance of infill pattern and $\mathrm{Cu}$ composition towards energy absorption is confirmed through statistical evaluation shown in Table 4. The confidence level is set to $95 \%(\alpha=0.05)$, the infill pattern and $\mathrm{Cu}$ composition have P-values of 0.001 and 0.005 , respectively, which are lower and equal to 0.05 , confirming these two parameters have a significant effect on energy absorption. Meanwhile, the second-order infill pattern and interaction between studied infill patterns with copper composition have a P-value higher than 0.05 , showing no significant effect towards energy absorbed.

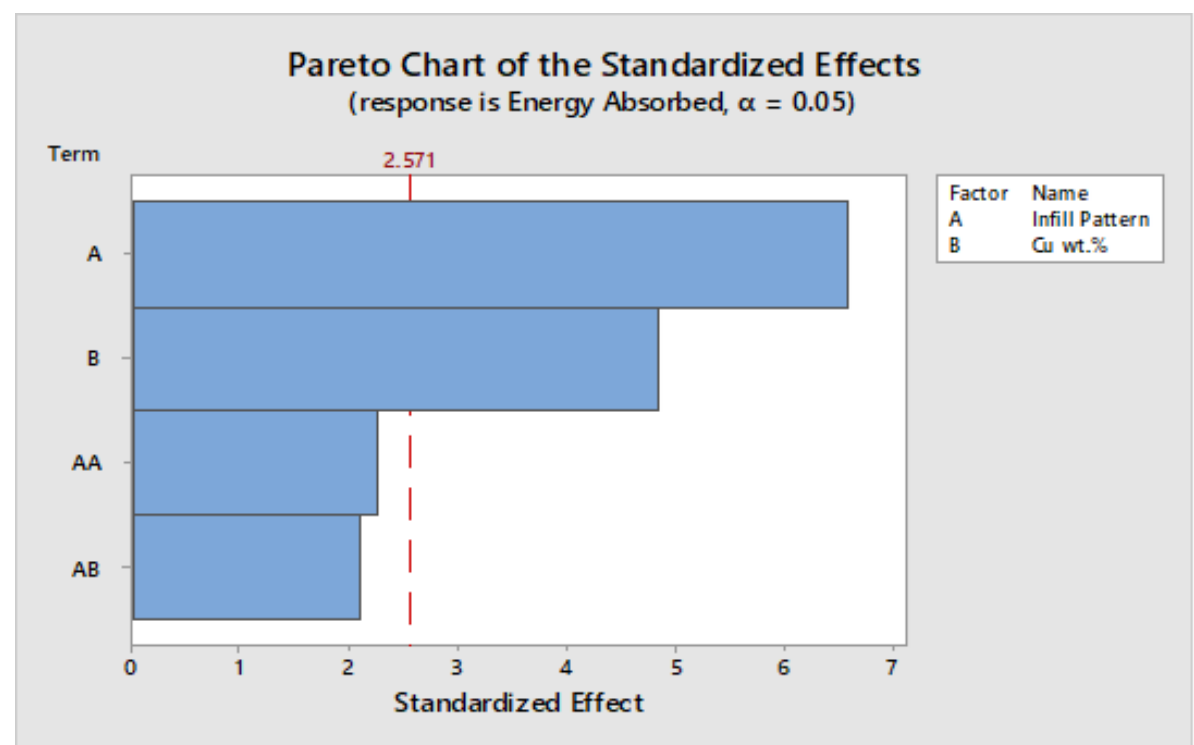

Fig. 4. Pareto effects of energy absorbed with respective experiment parameters

Table 4

ANOVA analysis for the energy absorbed

\begin{tabular}{|c|c|c|c|c|c|c|}
\hline Source & DF & Contribution & Adj SS & Adj MS & F-Value & P-Value \\
\hline Model & 4 & $93.85 \%$ & 4.1452 & 1.03629 & 19.08 & 0.003 \\
\hline Linear & 2 & $82.13 \%$ & 3.6274 & 1.81368 & 33.40 & 0.001 \\
\hline Infill Pattern & 1 & $53.33 \%$ & 2.3556 & 2.35561 & 43.38 & 0.001 \\
\hline Cu wt.\% & 1 & $28.79 \%$ & 1.2718 & 1.27175 & 23.42 & 0.005 \\
\hline Square & 1 & $6.28 \%$ & 0.2774 & 0.27737 & 5.11 & 0.073 \\
\hline Infill Pattern*Infill Pattern & 1 & $6.28 \%$ & 0.2774 & 0.27737 & 5.11 & 0.073 \\
\hline 2-Way Interaction & 1 & $5.44 \%$ & 0.2404 & 0.24043 & 4.43 & 0.089 \\
\hline Infill Pattern*Cu wt.\% & 1 & $5.44 \%$ & 0.2404 & 0.24043 & 4.43 & 0.089 \\
\hline Error & 5 & $6.15 \%$ & 0.2715 & 0.05430 & & \\
\hline Total & 9 & $100.00 \%$ & & & & \\
\hline \multicolumn{7}{|c|}{ Standard deviation $(\mathrm{S})=0.23303$} \\
\hline \multicolumn{7}{|l|}{$R^{2}=93.85 \%$} \\
\hline \multicolumn{7}{|l|}{$R^{2}$ - adjusted $=88.93 \%$} \\
\hline$R^{2}-$ predicted $=70.51 \%$ & & & & & & \\
\hline
\end{tabular}


According to Table 4, the P-value of the model is 0.003 , showing that the model created for the energy absorption is statistically significant. The model is shown in Eq. (1).

Energy absorbed (J)

$$
\begin{aligned}
& =0.76-0.045 * \text { Infill Pattern }-0.0101 * \text { Cu wt. } \%+0.0995 * \text { Infill Pattern } \\
& * \text { Infill Pattern }-0.00399 * \text { Infill Pattern } * \text { Cu wt. } \%
\end{aligned}
$$

Comparison between experimental results of energy absorbed with predicted values from the model in Eq. (1) is shown in Table 5. The average percentage error of the model as compared to experimental values is $14.76 \%$. The developed model exhibits satisfactory accuracy in order to predict energy absorption.

Table 5

Comparison of experimental and predicted energy absorbed

\begin{tabular}{lllll}
\hline Pattern & Cu wt.\% & Actual $(\mathrm{J})$ & Predicted $(\mathrm{J})$ & Error $(\%)$ \\
\hline 1.Grid & 25 & 0.6320 & 0.7042 & 11.4241 \\
2.Octagram-spiral & 25 & 0.9750 & 0.8376 & 14.0974 \\
3.Rectilinear & 25 & 1.3037 & 1.1843 & 9.1562 \\
4.Honeycomb & 25 & 1.3753 & 1.7445 & 26.8383 \\
5.Concentric & 25 & 2.6960 & 2.5180 & 6.6024 \\
1.Grid & 80 & 0.4113 & 0.4897 & 19.0519 \\
2.Octagram-spiral & 80 & 0.4733 & 0.3838 & 18.9155 \\
3.Rectilinear & 80 & 0.5847 & 0.4913 & 15.9692 \\
4.Honeycomb & 80 & 0.6615 & 0.8122 & 22.7816 \\
5.Concentric & 80 & 1.3850 & 1.3465 & 2.7798 \\
Average & & & & 14.7616 \\
\hline
\end{tabular}

The final analysis performed to determine maximum energy absorbed by response optimization. From the analysis, the maximum response of energy absorbed is determined to be achievable of $2.5180 \mathrm{~J}$ with the set of parameters with $25 \mathrm{wt}$.\% Cu and Concentric infill pattern. Since the suggested parameters have been included in the experiment, the optimized energy absorbed of $2.5180 \mathrm{~J}$ will be compared to the experimental value of $2.6960 \mathrm{~J}$, having an error of $6.60 \%$.

Figure 5 shows the Pareto effects of impact strength with respective experimental parameters. The illustration shows that infill pattern and $\mathrm{Cu}$ composition have a significant effect on impact strength. The significance of infill pattern and $\mathrm{Cu}$ composition towards impact strength is confirmed through statistical evaluation shown in Table 6. The confidence level is set to $95 \%(\alpha=0.05)$, the infill pattern and $\mathrm{Cu}$ composition have $P$-values of 0.001 and 0.005 , respectively, which are lower and equal to 0.05 , confirming these two parameters have a significant effect on impact strength. Meanwhile, the second-order infill pattern effect and interaction between studied infill pattern with copper composition have a $P$-value higher than 0.05 , showing no significant effect on impact strength. 


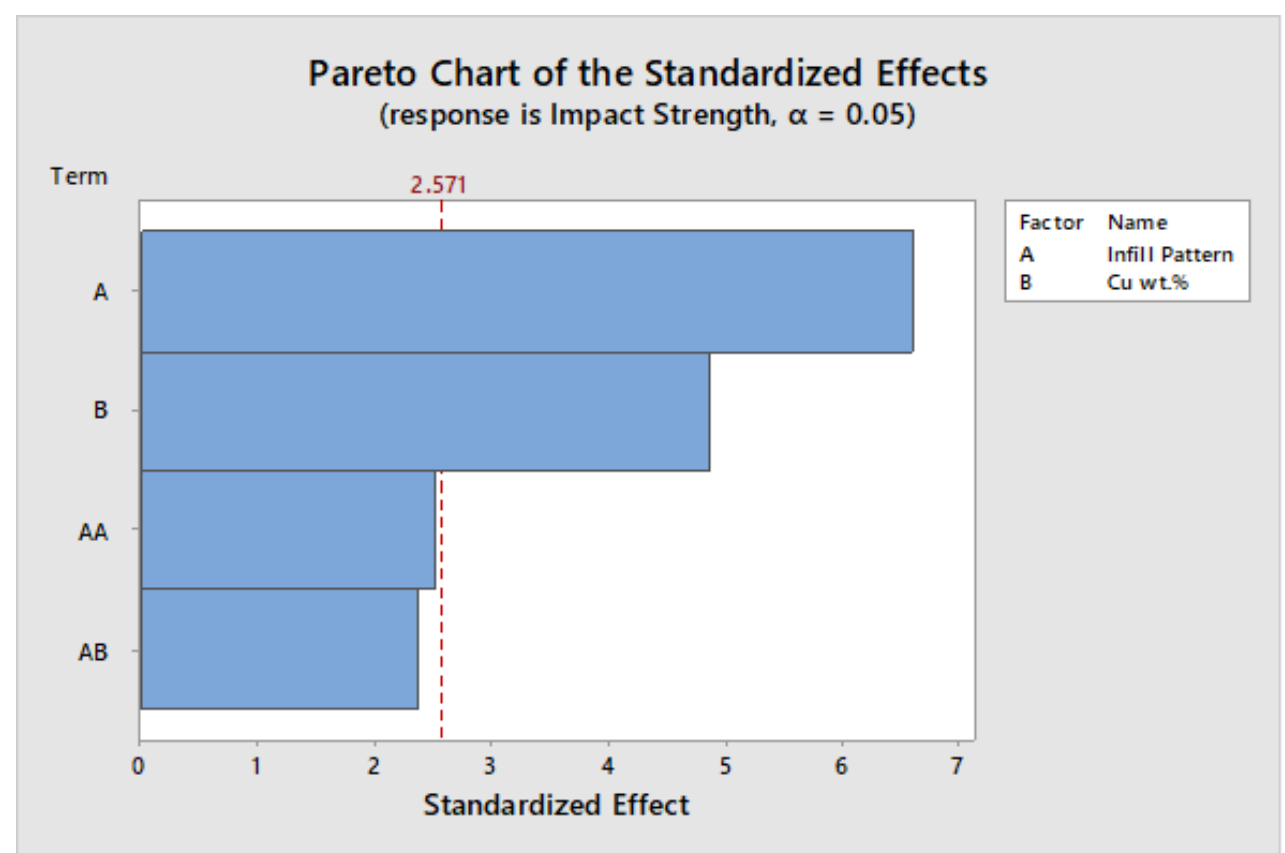

Fig. 5. Pareto effects of impact strength with respective experiment parameters

Table 6

ANOVA analysis of impact strength

\begin{tabular}{|c|c|c|c|c|c|c|}
\hline Source & $\mathrm{DF}$ & Contribution & Adj SS & Adj MS & F-Value & P-Value \\
\hline Model & 4 & $94.08 \%$ & 795.94 & 198.99 & 19.86 & 0.003 \\
\hline Linear & 2 & 79.94\% & 676.29 & 338.15 & 33.76 & 0.001 \\
\hline Infill Pattern & 1 & $51.83 \%$ & 438.47 & 438.47 & 43.77 & 0.001 \\
\hline Cu wt.\% & 1 & $28.11 \%$ & 237.83 & 237.83 & 23.74 & 0.005 \\
\hline Square & 1 & $7.43 \%$ & 62.87 & 62.87 & 6.28 & 0.054 \\
\hline Infill Pattern*Infill Pattern & 1 & $7.43 \%$ & 62.87 & 62.87 & 6.28 & 0.054 \\
\hline 2-Way Interaction & 1 & $6.71 \%$ & 56.78 & 56.78 & 5.67 & 0.063 \\
\hline Infill Pattern*Cu wt.\% & 1 & $6.71 \%$ & 56.78 & 56.78 & 5.67 & 0.063 \\
\hline Error & 5 & $5.92 \%$ & 50.09 & 10.02 & & \\
\hline Total & 9 & $100.00 \%$ & & & & \\
\hline \multicolumn{7}{|l|}{ Standard deviation $(S)=3.16498$} \\
\hline \multicolumn{7}{|l|}{$R^{2}=94.08 \%$} \\
\hline \multicolumn{7}{|l|}{$R^{2}-$ adjusted $=89.34 \%$} \\
\hline$R^{2}$ - predicted $=72.84 \%$ & & & & & & \\
\hline
\end{tabular}

According to Table 6, the P-value of the model is 0.003 , showing that the model created for impact strength is statistically significant. The model is shown in Eq. (2).

Impact strength $\left(\frac{\mathrm{kJ}}{\mathrm{m}^{2}}\right)$

$$
\begin{aligned}
& =10.86-1.09 * \text { Infill Pattern }+0.0065 * \text { Cu wt. } \%+1.498 * \text { Infill Pattern } \\
& * \text { Infill Pattern }-0.613 * \text { Infill Pattern } * \text { Cu wt. } \%
\end{aligned}
$$

Comparison between experimental results of impact strength with predicted values from the model in Eq. (2) is shown in Table 7. The average percentage error of the model as compared to 
experimental values is $14.80 \%$. The model can be deduced that it is able to predict impact strength with satisfactory accuracy.

Table 7

Comparison of experimental and predicted impact strength

\begin{tabular}{lllll}
\hline Pattern & Cu wt.\% & Actual $\left(\mathrm{kJ} / \mathrm{m}^{2}\right)$ & Predicted $\left(\mathrm{kJ} / \mathrm{m}^{2}\right)$ & Error $(\%)$ \\
\hline 1.Grid & 25 & 8.8864 & 9.898 & 11.3838 \\
2.Octagram-spiral & 25 & 13.7092 & 11.7695 & 14.1490 \\
3.Rectilinear & 25 & 18.3305 & 16.637 & 9.2388 \\
4.Honeycomb & 25 & 19.3382 & 24.5005 & 26.6948 \\
5.Concentric & 25 & 37.9078 & 35.3657 & 6.7210 \\
1.Grid & 80 & 5.7837 & 6.8840 & 19.0251 \\
2.Octagram-spiral & 80 & 6.6554 & 5.3840 & 19.1035 \\
3.Rectilinear & 80 & 8.2208 & 6.8800 & 16.3103 \\
4.Honeycomb & 80 & 9.2942 & 11.3720 & 22.3565 \\
5.Concentric & 80 & 19.4507 & 18.8600 & 3.0369 \\
Average & & & & 14.8020 \\
\hline
\end{tabular}

The final analysis was performed to determine maximum impact strength by response optimization. From the analysis, the maximum response of impact strengths was determined to be achievable as $35.3657 \mathrm{~kJ} / \mathrm{m}^{2}$ with the set of parameters with $25 \mathrm{wt} . \% \mathrm{Cu}$ and Concentric infill pattern. Since the suggested parameters have been included in the experiment, the optimized impact strength of $35.3657 \mathrm{~kJ} / \mathrm{m}^{2}$ will be compared to the experimental value of $37.9078 \mathrm{~kJ} / \mathrm{m}^{2}$, having an error of $6.72 \%$.

\section{Conclusions}

In conclusion, the test specimen is fabricated through a low-cost fused deposition modeling 3D printer with the incorporation of varying infill patterns and copper compositions based on ASTM standards. The impact test is conducted on the printed specimen with respect to the variation of copper composition and various infill patterns. The impact performance results were evaluated using response surface methodology, and reliable modeling for all impact properties was developed. Impact test showed that significant factors such as variation of infill pattern and copper composition show a substantial effect for both factors, including energy absorbed and impact strength. The highest energy absorbed is achieved by the Concentric infill pattern with $2.7 \mathrm{~J}$ by $25 \mathrm{wt} . \% \mathrm{Cu}$ and 1.39 $\mathrm{J}$ by $80 \mathrm{wt} . \% \mathrm{Cu}$. The Grid infill pattern has the lowest energy absorbed, recording $0.63 \mathrm{~J}$ and $0.41 \mathrm{~J}$ for 25 and 80 wt.\% copper composition. A Concentric infill pattern achieves the highest impact strength with $37.91 \mathrm{~kJ} / \mathrm{m}^{2}$ by $25 \mathrm{wt} . \% \mathrm{Cu}$ and $19.45 \mathrm{~kJ} / \mathrm{m}^{2}$ by $80 \mathrm{wt} . \% \mathrm{Cu}$. The Grid infill pattern has the lowest impact strength recording $8.89 \mathrm{~kJ} / \mathrm{m}^{2}$ and $5.78 \mathrm{~kJ} / \mathrm{m}^{2}$ for 25 and $80 \mathrm{wt} \%$ copper composition. The model created for the energy absorbed, and impact strength has an error of 7.23 $\%$ and $6.71 \%$. The maximum energy absorbed and impact strength can be obtained through the combination of effective parameters, including a Concentric infill pattern with 25 wt.\% copper composition.

\section{Acknowledgement}

The authors are grateful to Universiti Malaysia Pahang (www.ump.edu.my) and Green Kingdom Solutions Sdn. Bhd. for the financial support provided under the grants UIC190828, UIC190826, and UIC190827. 


\section{References}

[1] Srivatsan, T. S., and T. S. Sudarshan, eds. Additive manufacturing: innovations, advances, and applications. CRC Press, 2015. https://doi.org/10.1201/b19360

[2] Bikas, H., and P. Stavropoulos. "\& Chryssolouris, G." Additive manufacturing methods and modelling approaches: a critical review, The International Journal of Advanced Manufacturing Technology (2016): 389-405. https://doi.org/10.1007/s00170-015-7576-2

[3] Chacón, J. M., Miguel Angel Caminero, Eustaquio García-Plaza, and Pedro J. Núnez. "Additive manufacturing of PLA structures using fused deposition modelling: Effect of process parameters on mechanical properties and their optimal selection." Materials \& Design 124 (2017): 143-157. https://doi.org/10.1016/i.matdes.2017.03.065

[4] Yang, Yiran, Lin Li, Yayue Pan, and Zeyi Sun. "Energy consumption modeling of stereolithography-based additive manufacturing toward environmental sustainability." Journal of Industrial Ecology 21, no. S1 (2017): S168-S178. https://doi.org/10.1111/iiec.12589

[5] Oliveira, J. P., A. D. Lalonde, and J. Ma. "Processing parameters in laser powder bed fusion metal additive manufacturing 193 (2020) 1-12." (2020). https://doi.org/10.1016/i.matdes.2020.108762

[6] Yap, Yee Ling, Chengcheng Wang, Swee Leong Sing, Vishwesh Dikshit, Wai Yee Yeong, and Jun Wei. "Material jetting additive manufacturing: An experimental study using designed metrological benchmarks." Precision engineering 50 (2017): 275-285. https://doi.org/10.1016/i.precisioneng.2017.05.015

[7] Luong, Duy Xuan, Ajay K. Subramanian, Gladys A. Lopez Silva, Jongwon Yoon, Savannah Cofer, Kaichun Yang, Peter Samora Owuor et al. "Laminated object manufacturing of 3D-printed laser-induced graphene foams." Advanced Materials 30, no. 28 (2018): 1707416. https://doi.org/10.1002/adma.201707416

[8] Bhardwaj, Tarun, Mukul Shukla, C. P. Paul, and K. S. Bindra. "Direct energy deposition-laser additive manufacturing of titanium-molybdenum alloy: Parametric studies, microstructure and mechanical properties." Journal of Alloys and Compounds 787 (2019): 1238-1248. https://doi.org/10.1016/j.jallcom.2019.02.121

[9] Turner, Brian N., and Scott A. Gold. "A review of melt extrusion additive manufacturing processes: II. Materials, dimensional accuracy, and surface roughness." Rapid Prototyping Journal (2015). https://doi.org/10.1108/RPJ-012013-0012

[10] Kazmer, David. "Three-dimensional printing of plastics." In Applied Plastics Engineering Handbook, pp. 617-634. William Andrew Publishing, 2017. https://doi.org/10.1016/B978-0-323-39040-8.00029-8

[11] Sood, Anoop Kumar, R. K. Ohdar, and Siba Sankar Mahapatra. "Improving dimensional accuracy of fused deposition modelling processed part using grey Taguchi method." Materials \& Design 30, no. 10 (2009): 4243-4252. https://doi.org/10.1016/i.matdes.2009.04.030

[12] Sun, Q., G. M. Rizvi, C. T. Bellehumeur, and P. Gu. "Effect of processing conditions on the bonding quality of FDM polymer filaments." Rapid prototyping journal (2008). https://doi.org/10.1108/13552540810862028

[13] Chou, K., and Y. Zhang. "A parametric study of part distortion in fused deposition modeling using three dimensional element analysis." J. Eng. Manuf 222, no. 1 (2008): 959-967. https://doi.org/10.1243/09544054JEM990

[14] Nancharaiah, T. R. D. R. V., D. Ranga Raju, and V. Ramachandra Raju. "An experimental investigation on surface quality and dimensional accuracy of FDM components." International Journal on Emerging Technologies 1, no. 2 (2010): 106-111.

[15] Abbott, A. C., G. P. Tandon, R. L. Bradford, H. Koerner, and J. W. Baur. "Process-structure-property effects on ABS bond strength in fused filament fabrication. Addit. Manuf. 19, 29-38 (2018). https://doi.org/10.1016/j.addma.2017.11.002

[16] Ngo, Tuan D., Alireza Kashani, Gabriele Imbalzano, Kate TQ Nguyen, and David Hui. "Additive manufacturing (3D printing): A review of materials, methods, applications and challenges." Composites Part B: Engineering 143 (2018): 172-196. https://doi.org/10.1016/j.compositesb.2018.02.012

[17] Wang, Xin, Man Jiang, Zuowan Zhou, Jihua Gou, and David Hui. "3D printing of polymer matrix composites: A review $\begin{array}{llllll}\text { and } \quad \text { prospective." Composites } & \text { Part } & \text { B: } & \text { Engineering } 110 & \text { (2017): } & \text { 442-458. }\end{array}$ https://doi.org/10.1016/i.compositesb.2016.11.034

[18] Aslfattahi, Navid, R. Saidur, Mohd Faizul Mohd Sabri, and A. Arifutzzaman. "Experimental investigation on thermal stability and enthalpy of eutectic alkali metal solar salt dispersed with MgO nanoparticles." In The 4th International tropical renewable energy conference. 2019. https://doi.org/10.14716/ijtech.v10i6.3568

[19] Aslfattahi, Navid, R. Saidur, Nor Azwadi Che Sidik, Mohd Faizul Mohd Sabri, and Md Hasan Zahir. "Experimental assessment of a novel eutectic binary molten salt-based hexagonal boron nitride nanocomposite as a promising PCM with enhanced specific heat capacity." Journal of Advanced Research in Fluid Mechanics and Thermal Sciences 68, no. 1 (2020): 73-85. https://doi.org/10.37934/arfmts.68.1.7385

[20] Aslfattahi, Navid, R. Saidur, A. Arifutzzaman, Rad Sadri, Nuno Bimbo, Mohd Faizul Mohd Sabri, Philip A. Maughan et al. "Experimental investigation of energy storage properties and thermal conductivity of a novel organic phase 
change material/MXene as A new class of nanocomposites." Journal of Energy Storage 27 (2020): 101115. https://doi.org/10.1016/j.est.2019.101115

[21] Postiglione, Giovanni, Gabriele Natale, Gianmarco Griffini, Marinella Levi, and Stefano Turri. "Conductive 3D microstructures by direct 3D printing of polymer/carbon nanotube nanocomposites via liquid deposition modeling." Composites Part A: Applied Science and Manufacturing 76 (2015): 110-114. https://doi.org/10.1016/i.compositesa.2015.05.014

[22] Zhuang, Yuan, Wentong Song, Gang Ning, Xueyan Sun, Zhongzheng Sun, Guowei Xu, Bo Zhang, Yening Chen, and Shengyang Tao. "3D-printing of materials with anisotropic heat distribution using conductive polylactic acid composites." Materials \& Design 126 (2017): 135-140. https://doi.org/10.1016/i.matdes.2017.04.047

[23] Vogel, Julius, Michael R. Kessler, Sriram Sundararajan, and David Grewell. "Activation energy for diffusion and welding of PLA films." Polymer Engineering \& Science 52, no. $8 \quad$ (2012): $1693-1700$. https://doi.org/10.1002/pen.23120

[24] Letcher, Todd, and Megan Waytashek. "Material property testing of 3D-printed specimen in PLA on an entry-level 3D printer." In ASME 2014 international mechanical engineering congress and exposition. American Society of Mechanical Engineers Digital Collection, 2014. https://doi.org/10.1115/IMECE2014-39379

[25] Wittbrodt, Ben, and Joshua M. Pearce. "The effects of PLA color on material properties of 3-D printed components." Additive Manufacturing 8 (2015): 110-116. https://doi.org/10.1016/j.addma.2015.09.006

[26] King, D. L., A. Babasola, J. Rozario, and J. M. Pearce. "Development of mobile solar photovoltaic powered opensource 3-D printers for distributed customized manufacturing in off-grid communities." Challenges in Sustainability 2, no. 1 (2014): 18-27. https://doi.org/10.12924/cis2014.02010018

[27] Pei, Eujin, Antonio Lanzotti, Marzio Grasso, Gabriele Staiano, and Massimo Martorelli. "The impact of process parameters on mechanical properties of parts fabricated in PLA with an open-source 3-D printer." Rapid Prototyping Journal (2015). https://doi.org/10.1108/RPJ-09-2014-0135

[28] Tymark, B. M., M. Kreiger, and J. M. Pearce. "Mechanical properties of components fabricated with open-source 3D printers under realistic environmental conditions." Mater Des $58 \quad$ (2014): $242-246$. https://doi.org/10.1016/j.matdes.2014.02.038

[29] Song, Yichi, Yizhuo Li, Wenzhe Song, K. Yee, K-Y. Lee, and Vito L. Tagarielli. "Measurements of the mechanical response of unidirectional 3D-printed PLA." Materials \& Design $123 \quad$ (2017): 154-164. https://doi.org/10.1016/i.matdes.2017.03.051

[30] Nikzad, Mostafa, S. H. Masood, and Igor Sbarski. "Thermo-mechanical properties of a highly filled polymeric composites for fused deposition modeling." Materials \& Design 32, no. 6 (2011): 3448-3456. https://doi.org/10.1016/j.matdes.2011.01.056

[31] Hwang, S., and E. I. Reyes. "Moon, K. sik; Rumpf, RC; Kim, NS Thermo-mechanical Characterization of Metal." Polymer Composite Filaments and Printing Parameter Study for Fused Deposition Modeling in the 3D Printing Process. J. Electron. Mater 44 (2015): 771-777. https://doi.org/10.1007/s11664-014-3425-6

[32] Ko, Han-Seung, Sangwoon Lee, Doyoung Lee, and Jae Young Jho. "Mechanical Properties and Bioactivity of Poly (Lactic Acid) Composites Containing Poly (Glycolic Acid) Fiber and Hydroxyapatite Particles." Nanomaterials 11, no. 1 (2021): 249. https://doi.org/10.3390/nano11010249

[33] Hu, Chao, Jiaqi Dong, Junjie Luo, Qing-Hua Qin, and Guangyong Sun. "3D printing of chiral carbon fiber reinforced polylactic acid composites with negative Poisson's ratios." Composites Part B: Engineering 201 (2020): 108400. https://doi.org/10.1016/i.compositesb.2020.108400

[34] Siakeng, Ramengmawii, Mohammad Jawaid, Hidayah Ariffin, and S. M. Sapuan. "Mechanical, dynamic, and thermomechanical properties of coir/pineapple leaf fiber reinforced polylactic acid hybrid biocomposites." Polymer Composites 40, no. 5 (2019): 2000-2011. https://doi.org/10.1002/pc.24978

[35] Fattah-alhosseini, A., M. K. Keshavarz, A. Masomi, and S. Marianaji. "Semiconducting behavior of pure copper in alkaline solutions." Egyptian Journal of Petroleum 24, no. $4 \quad$ (2015): $405-409$. https://doi.org/10.1016/j.ejpe.2014.09.012

[36] Guschlbauer, Ralf, Soroush Momeni, Fuad Osmanlic, and Carolin Körner. "Process development of 99.95\% pure copper processed via selective electron beam melting and its mechanical and physical properties." Materials Characterization 143 (2018): 163-170. https://doi.org/10.1016/j.matchar.2018.04.009

[37] Gu, D. D., and Y. C. Hagedorn. "w. Meiners, k. wissenbach, R. Poprawe." Int. Mater. Rev 57, no. 3 (2012): 133. https://doi.org/10.1179/1743280411Y.0000000014

[38] Kain, S., J. V. Ecker, A. Haider, M. Musso, and A. Petutschnigg. "Effects of the infill pattern on mechanical properties of fused layer modeling (FLM) 3D printed wood/polylactic acid (PLA) composites." European Journal of Wood and Wood Products 78, no. 1 (2020): 65-74. https://doi.org/10.1007/s00107-019-01473-0 
[39] Hwang, Jaewon, Taeshik Yoon, Sung Hwan Jin, Jinsup Lee, Taek-Soo Kim, Soon Hyung Hong, and Seokwoo Jeon. "Enhanced mechanical properties of graphene/copper nanocomposites using a molecular-level mixing process." Advanced materials 25, no. 46 (2013): 6724-6729. https://doi.org/10.1002/adma.201302495 